\title{
Obesity in older people: A new scenario and a new challenger
}

\author{
José Eduardo Corrente ${ }^{1 *}$, Giovana Fumes ${ }^{2}$ and Patrícia Moraes Ferreira Nunes ${ }^{3}$ \\ ${ }^{1}$ Associate Professor, Biostatistics Department, Bioscience Institute, Univeristy of São Paulo State, Botucatu, São Paulo, Brazil \\ ${ }^{2}$ Exact Science Department, "Luiz de Queiroz" College of Agriculture, University of São Paulo, Piracicaba, São Paulo, Brazil \\ ${ }^{3}$ Public Health, Federal University of Espirito Santo, Espírito Santo, Brazil
}

\begin{abstract}
Obesity if the excess of body fat accumulated in the adipose tissue, developing diseases such as high blood pressure, diabetes, among other. Researches evaluating the scenario of obesity in older people no frequent in the literature. Then the aim of this work was to describe dietary patterns and it is association with general and central obesity as well as the macronutrient intake. A representative sample of 355 older people from Botucatu city, São Paulo, Brazil, was evaluated with sociodemographic and morbidities collected data. Also, a food frequency questionnaire (FFQ) was applied to obtain dietary patterns. Next, this data from FFQ was transformed into macronutrient intake. It was found that high adherence to healthy pattern is a protector general obesity and moderate adherence to Snacks and Weekend Meals pattern is a risk for central obesity. Also, some differences in macronutrient intake were found between obese and non-obese. As a conclusion, it is important a multidisciplinary team to develop new strategies and programs to encouraging a healthy eating in this age group.
\end{abstract}

\section{Introduction}

Obesity, according to WHO (2002), is the excess of body fat accumulated in the adipose tissue with implications to health. Obese people have more chance to develop diseases such as high blood pressure, diabetes, joint problems, breathing difficulties, gout, gallstones and even some forms of cancer.

Obesity happens when food intake is greater than the corresponding energy expenditure. One way to detect obesity is to calculate the Body Mass Index (BMI) which is calculated by dividing weight (in $\mathrm{kg}$ ) by the square of height (in meters), but that is not fully correlated with body fat. Since obesity is caused by an energy intake that exceeds the expense of the body, the simplest form of treatment is to adopt a healthier lifestyle, with less caloric intake and increased physical activity. This change not only causes weight reduction and reversal of obesity as well as facilitates the maintenance of healthy framework.

In addition to the excess weight, the accumulation of abdominal fat is also an important independent risk factor for cardiovascular disease and facilitates the development of insulin resistance, diabetes, high blood pressure and abnormal levels of cholesterol and triglycerides in the blood [1]. The combination of some of these factors characterizes the metabolic syndrome, responsible for this elevation in cardiac risk by $71 \%[2]$.

Many studies investigate socioeconomic and demographic determinants as well as eating behavior as a risk factor for overweight and obesity [3].

One way to evaluate the effect of food on health outcomes is the use of Eating Patterns that can be defined as "a set or a food groups consumed by a given population" [4]. This model allows identifying the synergistic action of food and nutrients in the risk of many chronic diseases and may help to capture some of the complexity of the diet [5]. These eating patterns may be the result of cultural heritage, ethnic and many environmental factors, including food availability, the ability to purchase and preparation of food and the numerous advertisements of products [6]. Then, the option of analyzing eating patterns can provide better benefits in proposing effective measures to promote health through food, which is the focus of nutritional epidemiology [7].

Then, the aim of the study was to describe dietary patterns of the olders and associate with central and abdominal obesity as well as with the macronutrient intake.

\section{Methodology}

Then, in the year of 2011, a cross-sectional study was carried out in Botucatu city, São Paulo, Brazil, in which anthropometric measures were obtained and a sociodemographic and a validated frequency food questionnaire (FFQ) were applied in a representative sample 355 older people. The sample size was calculating based on the number of items in the FFQ (71 food items). Following the recommendation of this sort of research, we considered five subjects for each item, totalizing the mentioned sample size.

\section{Results and discussion}

Results showed that $15.95 \%$ of men and $30.20 \%$ of female had general obesity and $42.94 \%$ of men and $74.47 \%$ of females had central obesity elderly. The highest prevalence regarding morbidities was hypertension (55.92\%), triglycerides (38.49\%) and diabetes mellitus (20.72\%). Major of them are married (60.6\%) and retired $(75 \%)$. The

Correspondence to: José Eduardo Corrente, Associate Professor, Biostatistics Department, Bioscience Institute, Univeristy of São Paulo State, Botucatu, São Paulo, Brazil, E-mail: jecorren@ibb.unesp.br

Key words: older people, dietary pattern, macronutrient intake

Received: July 12, 2016; Accepted: August 17, 2016; Published: August 20, 2016 
mean income was 1.76 two minimal wage (approximately US\$ 600.00 at that time).

Six dietary patterns were found: Healthy Foods, Snacks and Weekend meals, Fruits, Light and Whole food, Mild Diet and Traditional Diet. The scores of these patterns were divided in tertiles and classified as low, moderate and high adherence to the pattern. A logistic regression model was fitted considering the adherence of the pattern as a response variable and general and central obesity as an explanatory adjusted for age, marital status and alcohol consumption. Results are presented in Tables 1 and 2.

The high adherence to the Healthy pattern was a protective factor for general obesity (Table 1) as well as the moderate adherence to this pattern was a protective factor for abdominal obesity (Table 2). Already, moderate adherence to the pattern Snacks and Weekend meals was a risk factor for abdominal obesity (Table 2). These factors were obtained by adjusting for possible confounding variables such as age, marital status and alcohol consumption.

Data from FFQ were transformed in nutrient intake. A specific routine was developed in SAS (Statistical Analysis System) software for windows, v.9.3., based on the frequency of food consumption, number of times and the portion size.

Table 3 presents the consumption of nutrients with for sex and table 4 presents a consumption of nutrients considering general and central obesity stratified by sex adjusted for energy.
According to Table 3, there is a significant difference in energy intake between male and female. For other nutrients, no significance was found.

Related to the consumption of macronutrients (Table 4), it was obtained that general obese men had higher intakes of saturated fat. Now, for central obese, men had lower consumption of fiber and women had a higher consumption of protein and total fat.

The results found here added to the heterogeneity of eating patterns became possible the use of this work in future researches in order to evaluate the level of nutrient intake and the tendencies of risk for obesity in older people. May be this is a new scenario in obesity for older people.

As it was expected and according to our findings, people with high adherence to a Healthy pattern has less chance to be obese (general and central) but this does not mean that they adopt a consumption of healthy food. This can be observed when we analyze the macronutrient intake, as we cannot observe so much significant differences among them between obese and non-obese, male and female. Then, we can point out the importance of getting the eating patterns and the analysis of nutrient intake but also the importance of taking in account the quality of the diet, being a challenge for dietitians and other health professionals.

Some limitations of this study, which are common to most studies regarding food consumption, must be considered: a cross-

Table 1. Association between eating patterns and general obesity in older adults, according to the variables of interest (adjusted model*). Botucatu, São Paulo, Brazil, 2011.

\begin{tabular}{|c|c|c|c|c|c|}
\hline Variables & Categories of adherence & Estimate & Standard error & p-value & OR $($ IC $95 \%) * *$ \\
\hline & High & -0.6071 & 0.2134 & 0.0044 & $0.367(0.179-0.752)$ \\
\hline \multirow[t]{3}{*}{ 1-Healthy foods } & Moderate & 0.2112 & 0.1932 & 0.2742 & $0.831(0.434-1.592)$ \\
\hline & Low & 0 & - & - & 1 \\
\hline & High & -0.00364 & 0.2165 & 0.9866 & $1.104(0.514-2.370)$ \\
\hline \multirow[t]{3}{*}{ 2-Snacks and weekend meals } & Moderate & 0.1059 & 0.1964 & 0.5897 & $1.231(0.612-2.478)$ \\
\hline & Low & 0 & - & - & 1 \\
\hline & High & 0.3048 & 0.2048 & 0.1367 & $1.334(0.660-2.698)$ \\
\hline \multirow[t]{3}{*}{ 3-Fruits } & Moderate & -0.3211 & 0.2133 & 0.1323 & $0.714(0.343-1.484)$ \\
\hline & Low & 0 & - & - & 1 \\
\hline & High & 0.1981 & 0.2018 & 0.3263 & $1.485(0.728-3.029)$ \\
\hline \multirow[t]{3}{*}{ 4- Light and whole foods } & Moderate & -0.00053 & 0.205 & 0.9979 & $1.218(0.591-2.510)$ \\
\hline & Low & 0 & - & - & 1 \\
\hline & High & -0.0904 & 0.2069 & 0.6621 & $0.795(0.393-1.610)$ \\
\hline \multirow[t]{3}{*}{ 5- Mild diet } & Moderate & -0.048 & 0.1987 & 0.809 & $0.830(0.422-1.634)$ \\
\hline & Low & 0 & - & - & 1 \\
\hline & High & -0.3991 & 0.2113 & 0.0589 & $0.625(0.307-1.270)$ \\
\hline \multirow[t]{2}{*}{ 6-Traditional diet } & Moderate & 0.3275 & 0.1931 & 0.0899 & $1.292(0.676-2.467)$ \\
\hline & Low & 0 & - & - & 1 \\
\hline Age & - & -0.0591 & 0.0236 & 0.0122 & $0.943(0.900-0.987)$ \\
\hline \multirow[t]{2}{*}{ Marital Status } & Partner & 0.391 & 0.1667 & 0.019 & $2.186(1.137-4.202)$ \\
\hline & No partner & 0 & - & - & 1 \\
\hline \multirow[t]{2}{*}{ Alcohol consumption } & Consumption & 0.2046 & 0.1678 & 0.2225 & $1.506(0.780-2.906)$ \\
\hline & No consumption & 0 & - & - & 1 \\
\hline
\end{tabular}


Table 2. Association between eating patterns and abdominal obesity in older adults, according to the variables of interest (adjusted model*). Botucatu, São Paulo, Brazil 2011.

\begin{tabular}{|c|c|c|c|c|c|}
\hline Variables & Categories of adherence & Estimate & Standard error & p-value & OR (IC 95\%)** \\
\hline & High & 0.2062 & 0.1781 & 0.2469 & $1.045(0.570-1.914)$ \\
\hline \multirow[t]{3}{*}{ 1-Healthy foods } & Moderate & -0.3686 & 0.1746 & 0.0348 & $0.588(0.325-1.064)$ \\
\hline & Low & 0 & - & - & 1 \\
\hline & High & -0.0935 & 0.1824 & 0.6082 & $1.293(0.677-2.469)$ \\
\hline \multirow[t]{3}{*}{ 2-Snacks and weekend meals } & Moderate & 0.4436 & 0.1808 & 0.0141 & $2.212(1.164-4.203)$ \\
\hline & Low & 0 & - & - & 1 \\
\hline & High & 0.0981 & 0.1818 & 0.5895 & $1.455(0.779-2.716)$ \\
\hline \multirow[t]{3}{*}{ 3-Fruits } & Moderate & 0.1788 & 0.1793 & 0.3187 & $1.577(0.852-2.920)$ \\
\hline & Low & 0 & - & - & 1 \\
\hline & High & 0.1306 & 0.1818 & 0.4726 & $1.045(0.562-1.943)$ \\
\hline \multirow[t]{3}{*}{ 4- Light and whole foods } & Moderate & -0.2172 & 0.1838 & 0.2373 & $0.738(0.394-1.382)$ \\
\hline & Low & 0 & - & - & 1 \\
\hline & High & 0.1292 & 0.1805 & 0.474 & $1.047(0.565-1.939)$ \\
\hline \multirow[t]{3}{*}{ 5- Mild diet } & Moderate & -0.213 & 0.1761 & 0.2265 & $0.743(0.407-1.357)$ \\
\hline & Low & 0 & - & - & 1 \\
\hline & High & -0.2674 & 0.1755 & 0.1276 & $0.593(0.325-1.081)$ \\
\hline \multirow[t]{2}{*}{ 6-Traditional diet } & Moderate & 0.0115 & 0.1763 & 0.9478 & $0.783(0.428-1.433)$ \\
\hline & Low & 0 & - & - & 1 \\
\hline Age & - & -0.012 & 0.019 & 0.5279 & $0.988(0.952-1.026)$ \\
\hline \multirow[t]{2}{*}{ Marital status } & Partner & 0.1793 & 0.1447 & 0.2152 & $1.431(0.812-2.524)$ \\
\hline & No partner & 0 & - & - & 1 \\
\hline \multirow[t]{2}{*}{ Alcohol consumption } & Consumption & 0.1373 & 0.1464 & 0.3482 & $1.316(0.741-2.336)$ \\
\hline & No consumption & 0 & - & - & 1 \\
\hline
\end{tabular}

Table 3. Macro and micronutrients mean intake (adjusted for energy) according to sex of older people registered in the Basic Health Units of Botucatu city 2011.

\begin{tabular}{|c|c|c|}
\hline Nutrients & Male (Mean (SD)) & Female (Mean (SD)) \\
\hline Energy (kcal) & $2531.46(921.17)$ & $2026.20(737.31)$ \\
\hline Total fat (g) & $79,63(21.91)$ & $81.58(22.83)$ \\
\hline Saturated fat (g) & $26.10(8.85)$ & $27.01(9,39)$ \\
\hline Carbohydrates (g) & $267.36(61.44)$ & 0,5368 \\
\hline Protein (g) & $75.28(21.20)$ & 0,4717 \\
\hline Total fiber (g) & $27.07(8.85)$ & 0,7644 \\
\hline
\end{tabular}

Table 4. Macronutrients mean intake (adjusted for energy) according to sex and general and central obesity of older people registered in the Basic Health Units of Botucatu city, 2011.

\begin{tabular}{|c|c|c|c|c|c|c|}
\hline \multirow[b]{2}{*}{ Nutrients } & \multicolumn{3}{|c|}{ Male } & \multicolumn{3}{|c|}{ Female } \\
\hline & Non-obese & Obese & & Non-obese & Obese & \\
\hline General Obesity & Mean(SD) & Mean(SD) & p-value* & Mean(SD) & Mean(SD) & p-value* \\
\hline Energy (kcal) & $2514.00(894.94)$ & $2613.77(1292.18)$ & 0.7068 & $2083.50(765.66)$ & $1872.40(688.05)$ & 0.2267 \\
\hline Total fat (g) & $86.06(23.80)$ & $95.29(32.32)$ & 0.1338 & $73.25(21.61)$ & $79.68(22.85)$ & 0.1966 \\
\hline Saturated fat (g) & $28.09(9.83)$ & $32.94(13.82)$ & 0.0517 & $23.99(8.44)$ & $26.39(9.35)$ & 0,2352 \\
\hline Carbohydrates (g) & $301.07(64.10)$ & $287.02(78.46)$ & 0.4105 & $242.97(58.68)$ & $232.97(54.95)$ & 0.4457 \\
\hline Protein (g) & $80.96(20.47)$ & $90.59(28.63$ & 0.0757 & $64.09(19.64)$ & $68.64(20.60)$ & 0.3191 \\
\hline Total fiber (g) & $29.59(9.02)$ & $28.52(11.69)$ & 0.6753 & $24.99(8.43)$ & $22.51(7.50)$ & 0.1931 \\
\hline Central Obesity & Mean(SD) & Mean(SD) & p-value* & Mean(SD) & $\operatorname{Mean}(\mathrm{SD})$ & p-value* \\
\hline Energy (kcal) & $2418.33(854.75)$ & $2650.79(936.75)$ & 0.2467 & $2031.80(756.57)$ & $2022.92(711.08)$ & 0.9563 \\
\hline Total fat (g) & $90.45(23.69)$ & $84.84(22.48)$ & 0.2388 & $69.85(18.19)$ & 77.84 (21.32) & 0.0382 \\
\hline Saturated fat (g) & $28.84(9.73)$ & $29.20(10.05)$ & 0.8598 & $22.92(7.28)$ & $25.58(8.68)$ & 0.0795 \\
\hline Carbohydrates (g) & $307.85(63.36)$ & $288.45(58.70)$ & 0.1307 & $240.43(52.71)$ & $240.07(54.14)$ & 0.9722 \\
\hline Protein (g) & $84.36(20.75)$ & $80.97(20.05)$ & 0,4291 & $60.42(16.73)$ & $68.07(19.50)$ & 0.0358 \\
\hline Total fiber (g) & $31.22(9.22)$ & $27.46(8.12)$ & 0.0490 & $24.55(7.87)$ & $24.19(7.84)$ & 0.8205 \\
\hline
\end{tabular}

sectional design, which does not allow for the establishment of a causal relationship between risk factors and health outcomes. Individuals may either overestimate or underestimate the consumption of certain food items. Associations between eating patterns and obesity assumed the expected direction, and the control of covariables was performed, increasing the probability that the associations found are valid. However, since the purpose was to describe eating behaviors in order to guide immediate actions of health promotion, the priority was not to determine whether the relationship between food consumption and negative health outcomes is indeed casual.

\section{Conclusion}

As a conclusion, it is important to highlight the ongoing work of 
a multidisciplinary team that can guide this segment of the population and implement public policies to reduce obesity with awareness programs on nutrition and physical activity in this new scenario.

\section{References}

1. Amarya S, Singh K, Sabharwal M (2014) Health consequences of obesity in elderly. Journal of Clinical Gerontology and Geriatrics 3: 63-67.

2. Saad MA, Cardoso GP, Martins Wde A, Velarde LG, Cruz Filho RA (2014) Prevalence of metabolic syndrome in elderly and agreement among four diagnostic criteria. Arq Bras Cardiol102: 263-269. [Crossref]

3. Zalesin KC, Franklin BA, Miller WM, Peterson ED, McCullough PA (2008) Impact of obesity on cardiovascular disease. Endocrinol Metab Clin North Am 37: 663-684. [Crossref]

4. Ferreira PM, Papini SJ, Corrente JE (2014) Diversity of eating patterns in older adults: a new scenario. Brazilian Journal of Nutrition 27: 67-79.

5. Jacobs DR, Tapsell LC (2013) Food synergy: the key to a healthy diet. Proc Nutr Soc72: 200-206. [Crossref]

6. Gracia-Arnaiz M (2010) Fat bodies and thin bodies. Cultural, biomedical and market discourses on obesity. Appetite 55: 219-225. [Crossref]

7. Willett WC, McCullough ML (2008) Dietary pattern analysis for the evaluation of dietary guidelines. Asia Pac J Clin Nutr 17: 75-78. [Crossref]

Copyright: $\mathbb{C} 2016$ Corrente JE. This is an open-access article distributed under the terms of the Creative Commons Attribution License, which permits unrestricted use, distribution, and reproduction in any medium, provided the original author and source are credited. 